Supporting Information

\title{
"One-step" Carbonization Activation of Garlic Seeds for Honeycomb-like Hierarchical Porous Carbon and its High Supercapacitor Properties
}

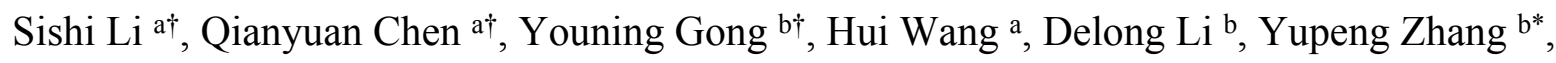
Qiang $\mathrm{Fu}^{\mathrm{c}}$, Chunxu Pan a, ${ }^{\mathrm{c}}$

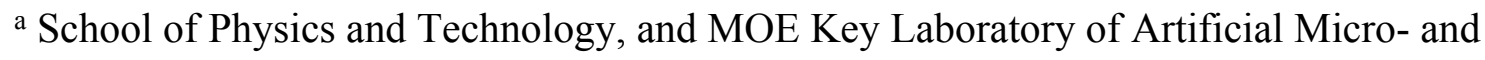
Nano-structures, Wuhan University, Wuhan 430072, China.

${ }^{\mathrm{b}}$ Institute of Microscale Optoelectronics, Shenzhen Key Laboratory of Flexible Memory Materials and Devices, Shenzhen University, Shenzhen 518000, China.

${ }^{\mathrm{c}}$ Center for Electron Microscopy, Wuhan University, Wuhan 430072, China.

$\dagger$ These authors contributed equally to this work.

* Author to whom correspondence should be addressed.

E-mail: ypzhang@szu.edu.cn (Y. Zhang), cxpan@whu.edu.cn (C. Pan) 


\section{Table and Figure captions}

Table S1 Geometric parameters of the h-HPC at different carbonization temperatures HPC-600 $\left(600^{\circ} \mathrm{C}\right)$, HPC-700 $\left(700^{\circ} \mathrm{C}\right)$ and HPC-800 $\left(800^{\circ} \mathrm{C}\right)$. (Total surface: $\mathrm{S}_{\mathrm{BET}}$; total pore volume: $\mathrm{V}_{\text {Total }}$; average pore diameter: $\mathrm{d}_{\mathrm{a}}$ )

Table S2 Geometric parameters of the h-HPC at different mass ratios of $\mathrm{KOH}$ and garlic seeds, i.e., HPC-0.5 (1:2), HPC-1 (1:1), HPC-2 (2:1), HPC-3 (3:1). (Total surface: $\mathrm{S}_{\mathrm{BET}}$; total pore volume: $\mathrm{V}_{\text {Total}}$; average pore diameter: $\mathrm{d}_{\mathrm{a}}$ )

Figure S1 SEM morphologies of the h-HPC at different carbonization temperatures. (a) $600^{\circ} \mathrm{C}$ (HPC-600); (b) $700^{\circ} \mathrm{C}$ (HPC-700); (c) $800^{\circ} \mathrm{C}$ (HPC-800).

Figure S2 SEM morphologies of the h-HPC at different mass ratios of KOH and garlic seeds. (a) HPC-0.5 (1:2); (b) HPC-1 (1:1); (c) HPC-2 (2:1); (d) HPC-3 (3:1).

Figure S3 High-resolution O 1s of the h-HPC.

Figure S4 Nyquist plots of the symmetric supercapacitor in a three-electrode system in 6 $\mathrm{mol} / \mathrm{L} \mathrm{KOH}$ electrolyte over the frequency range from $0.01 \mathrm{~Hz}$ to $100 \mathrm{kHz}$ : (a) total plot; (b) local plot in high frequancy range of (a); (c) total plot before cycle and after cycle; (d) local plot in high frequancy of $(c)$. $\left(Z^{\prime}=\right.$ real impedance and $-Z^{\prime}$ '= imaginary impedance).

Figure S5 (a, b) Nitrogen adsorption-desorption isotherm; (c, d) Pore size distribution curve of the h-HPC at different carbonization temperatures $\left(600^{\circ} \mathrm{C}, 700^{\circ} \mathrm{C}\right.$ and $\left.800{ }^{\circ} \mathrm{C}\right)$; (e, f) Pore size distribution curves of the h-HPC at different mass ratios of $\mathrm{KOH}$ and garlic seeds (HPC-0.5 (1:2), HPC-1 (1:1), HPC-2 (2:1) and HPC-3 (3:1))

Figure S6 Coulombic efficiency at different current densities (0.5 to $20.0 \mathrm{~A} / \mathrm{g})$; (a) h-HPC-based symmetrical supercapacitors in $6 \mathrm{~mol} / \mathrm{L} \mathrm{KOH}$ electrolyte; (b) h-HPC electrode in three-electrode system in $6 \mathrm{~mol} / \mathrm{L} \mathrm{KOH}$ electrolyte. 
Table S1 Geometric parameters of the h-HPC at different carbonization temperatures HPC-600 $\left(600^{\circ} \mathrm{C}\right)$, HPC-700 $\left(700^{\circ} \mathrm{C}\right)$ and HPC-800 $\left(800^{\circ} \mathrm{C}\right)$. (Total surface: $\mathrm{S}_{\mathrm{BET}}$; total pore volume: $\mathrm{V}_{\text {Total}}$; average pore diameter: $\mathrm{d}_{\mathrm{a}}$ )

\begin{tabular}{cccc}
\hline Sample & $\mathrm{S}_{\mathrm{BET}}\left(\mathrm{m}^{2} / \mathrm{g}\right)$ & $\mathrm{V}_{\text {Total }}\left(\mathrm{cm}^{2} / \mathrm{g}\right)$ & $\mathrm{d}_{\mathrm{a}}(\mathrm{nm})$ \\
\hline HPC-600 & 677.1 & 0.41 & 4.69 \\
HPC-700 & 1417.1 & 0.87 & 2.44 \\
HPC-800 & 945.8 & 0.73 & 3.85 \\
\hline
\end{tabular}

Table S2 Geometric parameters of the h-HPC at different mass ratios of $\mathrm{KOH}$ and garlic seeds, i.e., HPC-0.5 (1:2), HPC-1 (1:1), HPC-2 (2:1), HPC-3 (3:1). (Total surface: $\mathrm{S}_{\mathrm{BET}}$; total pore volume: $\mathrm{V}_{\text {Total }}$; average pore diameter: $\mathrm{d}_{\mathrm{a}}$ )

\begin{tabular}{cccc}
\hline Sample & $\mathrm{S}_{\mathrm{BET}}\left(\mathrm{m}^{2} / \mathrm{g}\right)$ & $\mathrm{V}_{\text {Total }}\left(\mathrm{cm}^{2} / \mathrm{g}\right)$ & $\mathrm{d}_{\mathrm{a}}(\mathrm{nm})$ \\
\hline HPC-0.5 & 876.6 & 0.61 & 4.19 \\
HPC-1 & 1417.1 & 0.87 & 2.44 \\
HPC-2 & 870.2 & 0.80 & 5.81 \\
HPC-3 & 825.5 & 0.69 & 5.98 \\
\hline
\end{tabular}



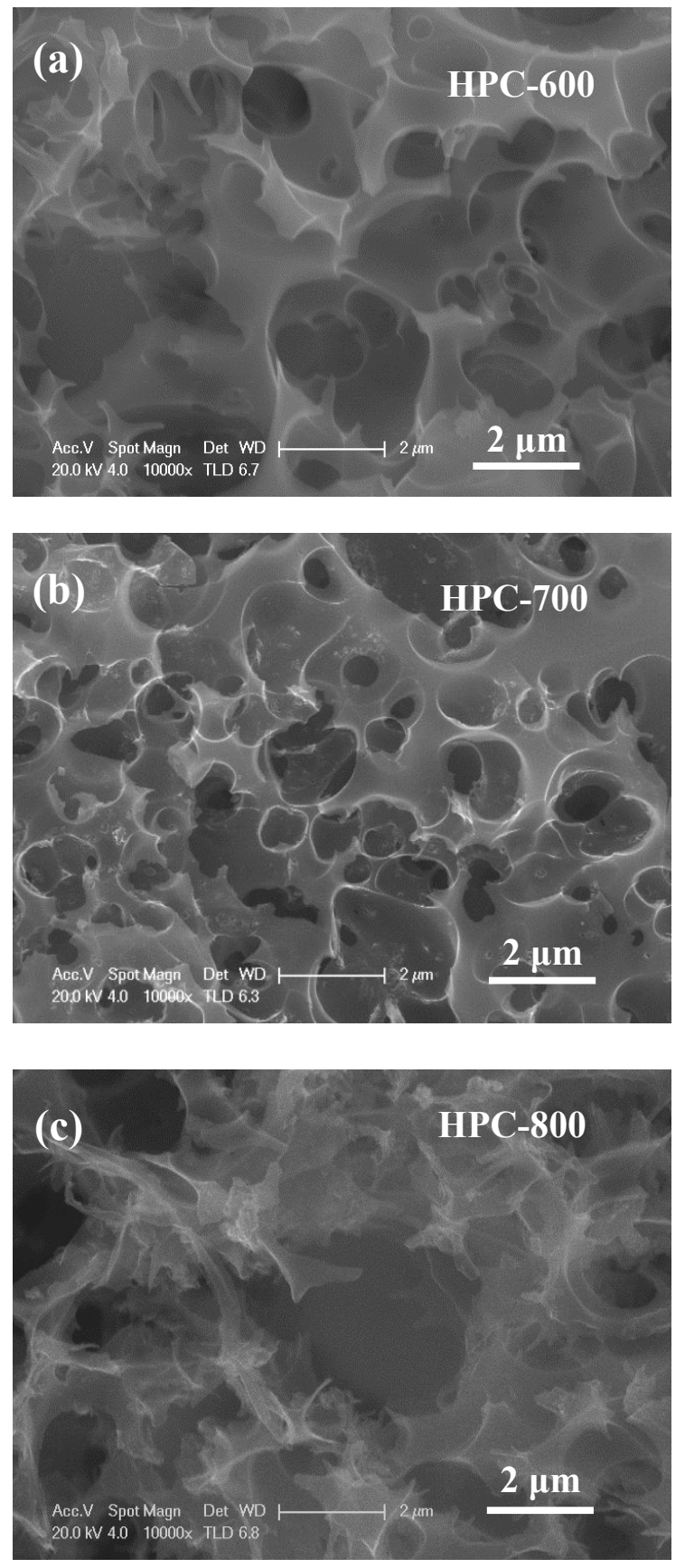

Figure S1 SEM morphologies of the h-HPC at different carbonization temperatures. (a) $600^{\circ} \mathrm{C}$ (HPC-600); (b) $700^{\circ} \mathrm{C}$ (HPC-700); (c) $800^{\circ} \mathrm{C}$ (HPC-800). 

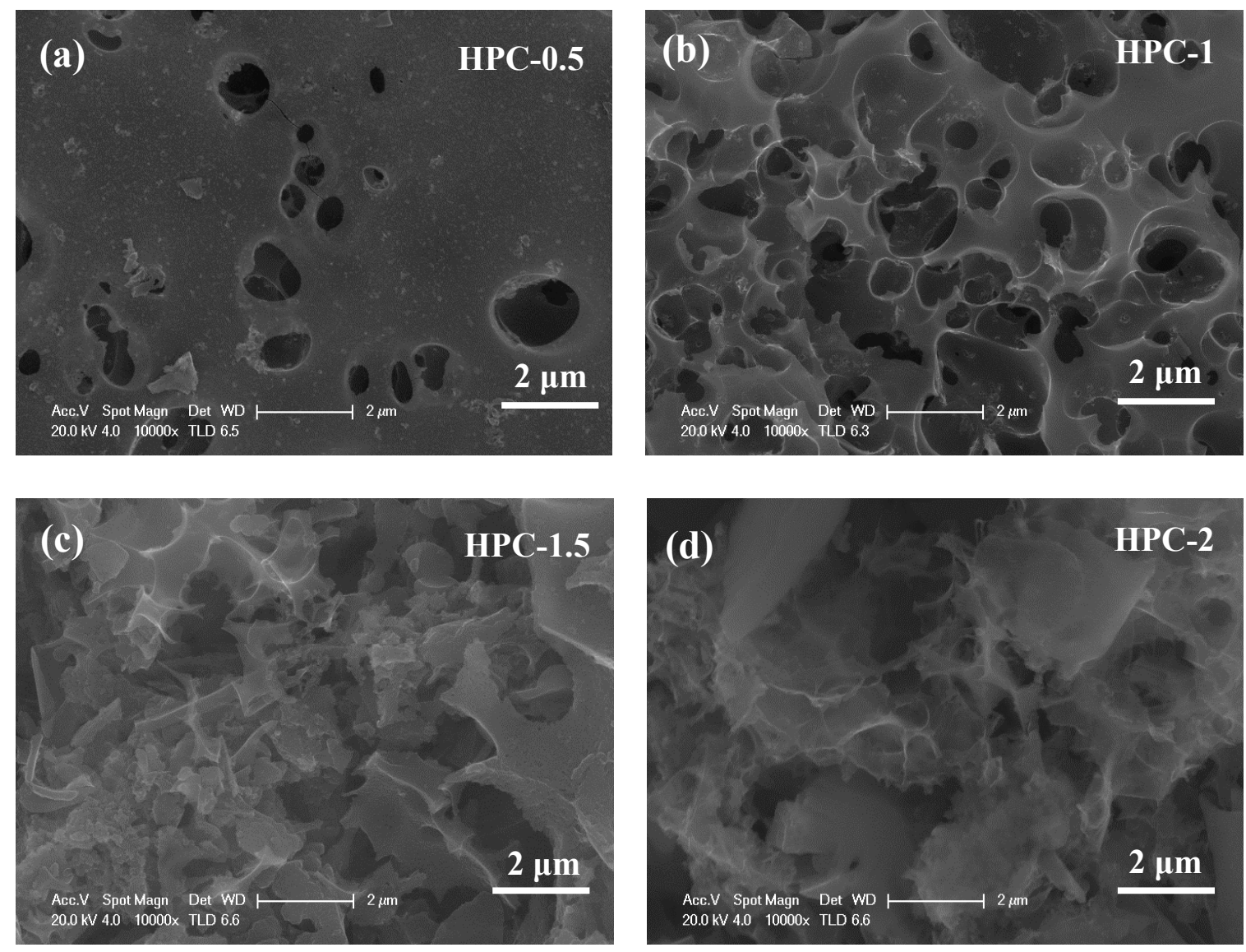

Figure S2 SEM morphologies of the h-HPC at different mass ratios of $\mathrm{KOH}$ and garlic seeds.

(a) HPC-0.5 (1:2); (b) HPC-1 (1:1); (c) HPC-2 (2:1); (d) HPC-3 (3:1). 


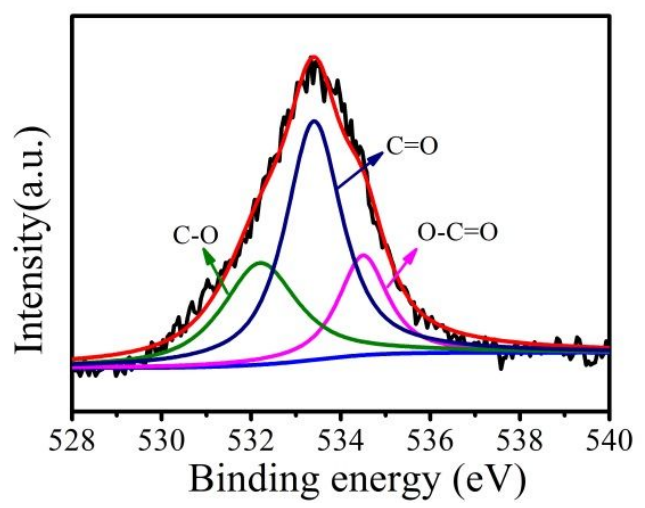

Figure S3 High-resolution O 1s of the h-HPC. 

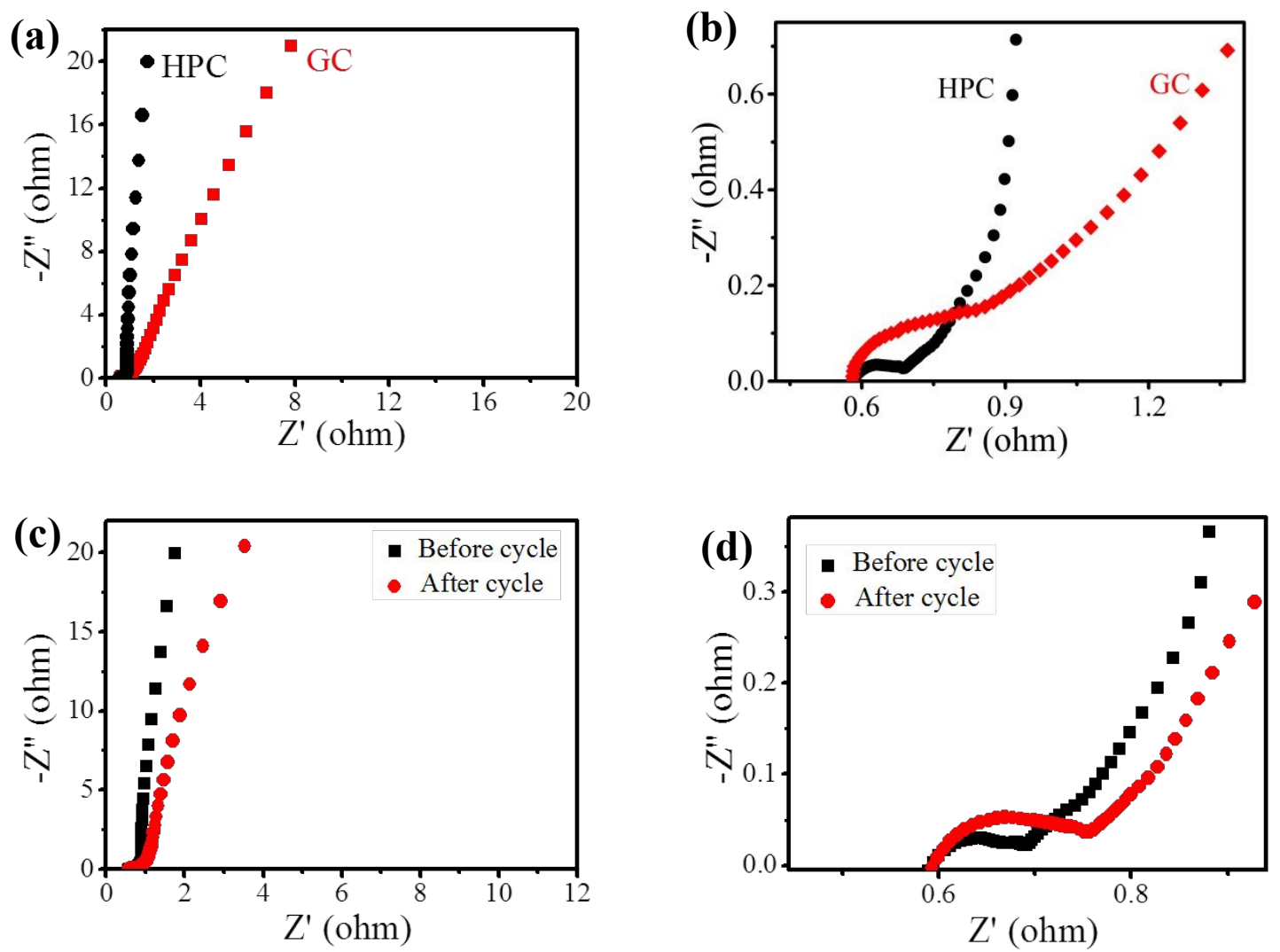

Figure S4 Nyquist plots of the symmetric supercapacitor in a three-electrode system in 6 mol/L KOH electrolyte over the frequency range from $0.01 \mathrm{~Hz}$ to $100 \mathrm{kHz}$ : (a) total plot; (b) local plot in high frequancy range of (a); (c) total plot before cycle and after cycle; (d) local plot in high frequancy of (c). ( $Z^{\prime}=$ real impedance and $-Z$ ''= imaginary impedance). 
(a)
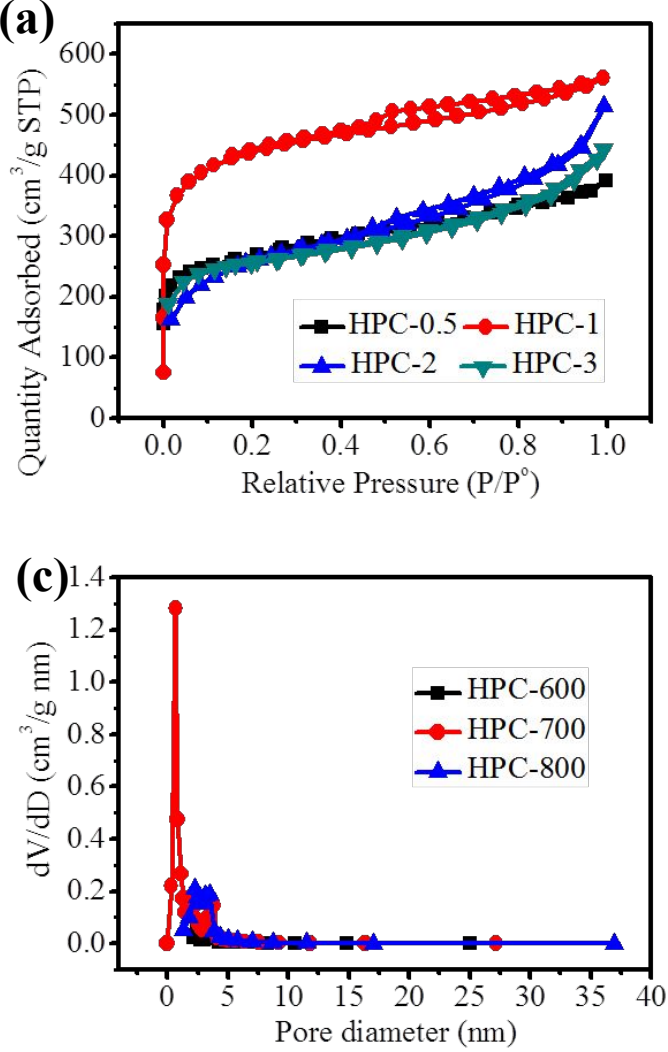

(e)

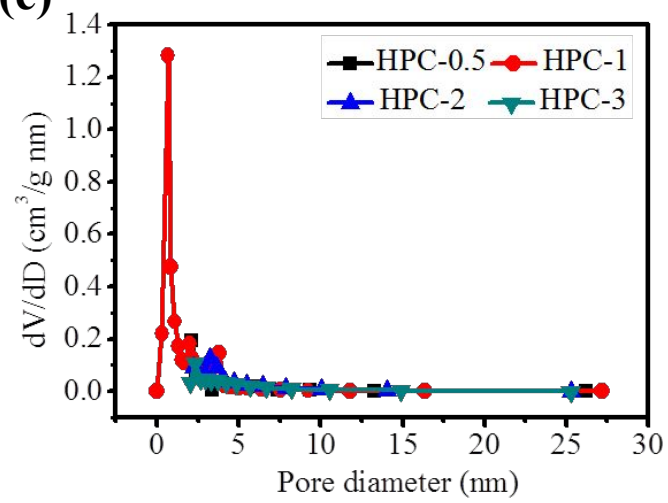

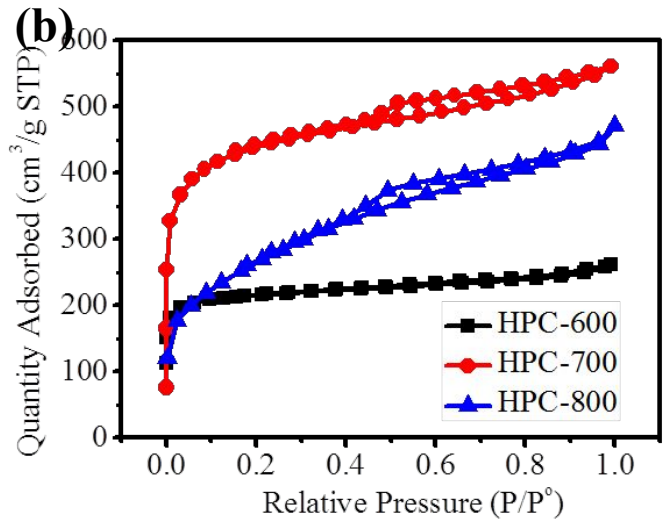
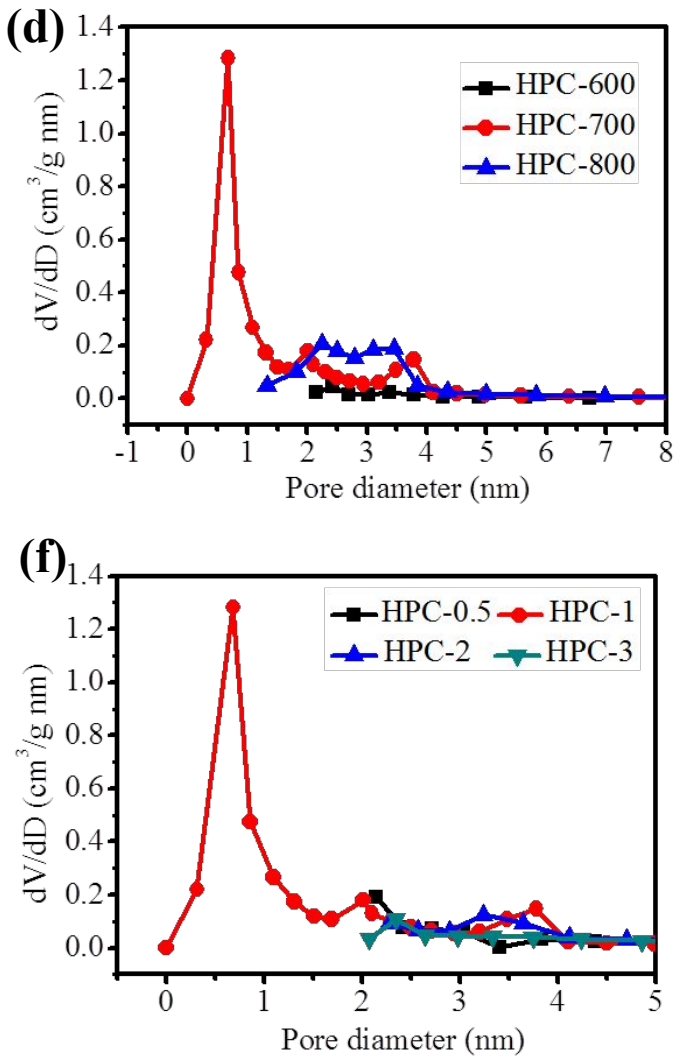

Figure S5 (a, b) Nitrogen adsorption-desorption isotherm; (c, d) Pore size distribution curve of the h-HPC at different carbonization temperatures $\left(600^{\circ} \mathrm{C}, 700{ }^{\circ} \mathrm{C}\right.$ and $\left.800{ }^{\circ} \mathrm{C}\right) ;(\mathrm{e}, \mathrm{f})$ Pore size distribution curves of the h-HPC at different mass ratios of $\mathrm{KOH}$ and garlic seeds (HPC-0.5 (1:2), HPC-1 (1:1), HPC-2 (2:1) and HPC-3 (3:1)) 
(a)

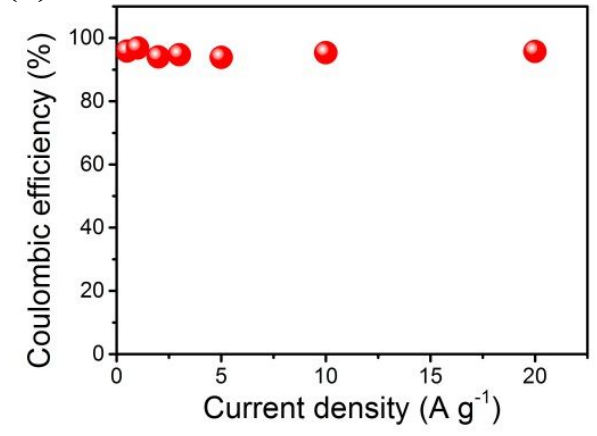

(b)

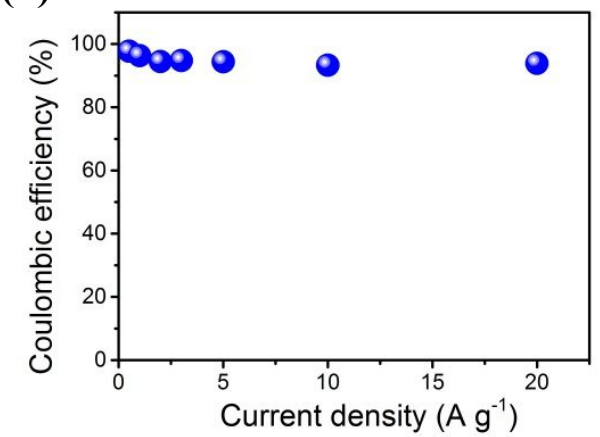

Figure S6 The coulombic efficiency at different current densities (0.5 to $20.0 \mathrm{~A} / \mathrm{g})$; (a) h-HPC-based symmetrical supercapacitors in $6 \mathrm{~mol} / \mathrm{L} \mathrm{KOH}$ electrolyte; (b) h-HPC electrode in three-electrode system in $6 \mathrm{~mol} / \mathrm{L} \mathrm{KOH}$ electrolyte. 